\title{
Pandeminin Kadına Yönelik Şiddet Üzerine Etkisinin Yazılı Basına Yansıyan Olgular Üzerinden İncelenmesi
}

\author{
DOI: $10.26466 /$ opus.947704
}

\author{
Hande SSahin $^{*}$ - Aygen Çakmak ${ }^{* *}$ - Yurdagül Erdem*** \\ * Prof. Dr., Kırıkkale Üniversitesi, Kırıkkale/Türkiye \\ E-Posta: hande_k1979@yahoo.com \\ ORCID: 0000-0002-0012-0294 \\ ** Doç.Dr, Kırıkkale Üniversitesi, Kırıkkale/Türkiye \\ E-Posta: ayalp71@gmail.com \\ ORCID: 0000-0003-0692-336X \\ *** Prof. Dr., Kırıkkale Üniversitesi, Kırıkkale/Türkiye \\ E-Posta: erdemyurd@gmail.com \\ ORCID:
}

Öz

Bu çalışmada, pandeminin kadına yönelik şiddet üzerine etkisinin yazıl basına yansıyan olgular üzerinden incelenmesi amaçlanmıştır. Çalışmada kadına yönelik şiddet haberleri tirajı en yüksek üç ulusal gazetenin çeorimiçi sürümlerinde 10.03.2019 ve 10.03.2021 tarihleri arasinda retrospektif olarak incelenmiştir. Bu gazetelerde "kadina yönelikşiddet,"," "kadın cinayeti,"," "öldürülen kadınlar," "kadin kurban," "kadın istismarn" ve "darp edilen kadın" anahtar sözcükleri kullanilarak tarama yapılmıştır. Farklı gazetelerde yer alan aynı haber ya da haftanın farkh günlerinde tekrar yayınlanan aynı haberler bir kez ele alınmıştır. Pandemi öncesi 98, pandemi döneminde 138 olmak üzere toplamda 236 habere ulaşılmıştır. Çalısma sonucunda şiddet mağduru kadınların büyük kısmının evli olduğu, pandemi öncesi ve pandemi döneminde şiddete eşleri tarafindan ve "kıskançlı" nedeniyle maruz kaldıkları, özellikle pandemi döneminde kadınm ayrlmak istediği için daha fazla şiddet gördü̆̈̈̈ ve Ege Bölgesi ile Karadeniz Bölgesi'nde kadina yönelik şiddete dair gazete haberlerinde artış olduğu belirlenmiştir. Özellikle pandemi öncesi ve sonrasinda gazete haberlerine yansıldı̆̆ şekliyle kadınlara uygulanan şiddet türünün fiziksel şiddet oldŭ̆u, kadınlarm ateşli silah ile öldürülmesinin pandemi döneminde pandemi öncesine göre daha yoğun görüldüğü ve kadınlarm bu şiddete kendi evlerinde ve genel olarak bakıldlğında gündüz vakitleri maruz kaldıklar saptanmıştır. Pandemi döneminde gazete haberlerine yansıyan şiddet olayı sonucu gerçekleşen kadın cinayeti vakalarının ve tutuklu durumundaki şiddet faillerinin oranlarında artış olduğ u belirlenmiştir.

Anahtar Kelimeler: Kadına Yönelik Şiddet, Gazete, Haber, Pandemi, Kadın Cinayeti. 


\title{
Examination of the Impact of the Pandemic on Violence against Women on Written Press
}

\begin{abstract}
This study aimed to examine the impact of the pandemic on violence against women through the cases reflected in the print media. In the study, news items on violence against women in the online versions of three national newspapers with the highest circulation rates were examined retrospectively between 10.03.2019 and 10.03.2021. These newspapers were scanned using the keywords "violence against women," "femicide," "killed women," "female victim," "female abuse," and "battered woman." The same news in different newspapers or the same news published again on different days of the week was taken as a single item. A total of 236 news items were reached, 98 of which were before the pandemic and 138 during the pandemic. As a result of the study, it was determined that most of the women who became victims of violence were married, they were exposed to violence by their spouses and because of "jealousy" before the pandemic and during the pandemic period, women were exposed to more violence because they wanted to leave especially during the pandemic period, , and there was an increase in the news about violence against women in the Aegean Region and the Black Sea Region. Especially before and after the pandemic, the type of violence applied to women as reflected in the news is physical violence. Also, it was found out that there was an increase in the rates of femicide due to violence against women as reflected in the news and the perpetrators of violence in detention.
\end{abstract}

Keywords: Violence Against Women, Newspaper, News, Pandemic, Femicide. 


\section{Giriş}

Aile içi şiddet, hem şiddetin yayginlığ mortalite oranı nedeniyle dünya çapında bir halk sağllğı önceliğidir (WHO, 2013). Aile içi şiddetin en yaygın şekli kadına ve çocuğa uygulanan şiddettir. 6284 Sayılı Ailenin Korunması ve Kadına Karşı Şiddetin Önlenmesine Dair Kanun kadına yönelik şiddeti, "kadınlara, yalnızca kadın oldukları için uygulanan veya kadınları etkileyen cinsiyete dayalı bir ayrımcılık ile kadının insan hakları ihlaline yol açan ve bu kanunda şiddet olarak tanımlanan her türlü tutum ve davranış" şeklinde tanımlanmaktadır (Resmi Gazete, 2012). Kadınlara yönelik şiddet dünyanın tüm ülkelerinde görülmekte ve günümüzün çözülmemiş en ciddi sorunlarından biri olmaya devam etmektedir. Kadına yönelik şiddetin farklı biçimleri söz konusudur. Bunlar fiziksel, psikolojik, cinsel ve ekonomik şiddettir. Avrupa'da kadınların \% 12 ila \% 15'i günlük olarak aile içi şiddetle karşı karşıya kalmaktadır (Akhmedshina, 2020). Dünya Sağlık Örgütü tarafından 10 ülkede 2497 kadın ile yapılan çalışmada fiziksel ya da cinsel şiddetin yaygınlığının \%15-71 arasında olduğu belirtilmiştir (Garcia, Jansen, Ellsberg, Heise ve Watts, 2006). Türkiye'de 2009 yılı Kadına Yönelik Aile İçi Şiddet Araştırması'nda ise aile içi fiziksel ve/veya cinsel şiddet yaygınlığı \%42 oranında iken, bu oran 2014 yılında \%37.5 olarak bildirilmiştir (Aile, Çalışma ve Sosyal Hizmetler Bakanlığı, 2009; TÜİK, 2014). Türkiye Kadın Dernekleri Federasyonu (TKDF) ise; pandemi sürecinde fiziksel şiddetin \%80, psikolojik şiddetin \%93, sığınma evi talebinin ise $\% 78$ arttı̆̆ını saptamıştır (TKDF, 2020).

Kadınlara karşı şiddet, toplumsal cinsiyet ilişkilerinin eşit olmamasının tek nedeni olmamakla birlikte en temel mekanizmalarından biridir (Gül-Sallan ve Altındal, 2015). Kadına yönelik şiddetin toplumun her kesiminde çok ağır etkileri olsa da şiddetin en ağır faturasını yaşam hakkı elinden alınmış kadınlar ödemektedir. Kadın intihar vakaları da şüpheli kadın cinayetlerinde önemli bir paya sahiptir. "Namusun temizlenmesi" ve "törenin gerçekleştirilmesi" adı altında işlenen kadın cinayetleri, uzun yıllardan beri ülkemizde önemli bir sorun alanına dikkat çekmektedir. Kadın cinayetlerinin haklı bir gerekçesi olarak sunulmaya çalışılan ve toplumda kabul gören bu anlayış pek çok kadının intiharının ve şüpheli pek çok kadın cinayetinin de sorumlusu konumundadır (Güneş ve Yıldırım, 2009). 
Kadına yönelik şiddet aynı zamanda din, dil, ırk farkı olmadan dünyanın her yerinde, kadın ve kızların yaşamları boyunca maruz kaldıkları bir insan hakkı ihlalidir. 1993 yılında Birleşmiş Milletler'in Kadına Yönelik Şiddetin Önlenmesi Bildirgesi, kadına yönelik şiddetin resmi bir tanımını sunarak kadına yönelik şiddeti: "fiziksel, cinsel veya psikolojik zarar veya acı ile sonuçlanan veya sonuçlanması muhtemel olan herhangi bir cinsiyet temelli şiddet eylemi, ister kamusal ister özel hayatta olsun, bu tür eylemlerin tehditle, zorlama veya özgürlüğünden keyfi olarak kadının yoksun bırakılması" olarak tanımlamıştır. Bu tanım, o zamandan beri Pekin Deklarasyonu ve Eylem Platformunda benimsenmiş ve uluslararası toplumda kabul edilmiştir (UNESCAP, 2021). Toplumsal cinsiyet eşitliğinin sağlanması açısından İstanbul Sözleşmesi'nin yürürlüğe girmesi Türkiye'nin en önemli güncel kazanımlarından biri olmuştur. Türkiye'nin ilk imzacısı olduğu bu sözleşmeye referans alarak hazırlanan 6284 Sayılı Ailenin ve Kadına Yönelik Şiddetin Önlenmesine Dair Kanun'un 2012 yılında çıkarılması hem şiddet ile mücadele hem de toplumsal cinsiyet eşitliği açısından önemli bir adımdır (Yüksel-Kaptanoğlu,2018). Ancak, Türkiye bu sözleşmeden 2021 Mart ayında çıkmıştır. Kanunun uygulamasına ilişkin sorunlar ve bu bağlamda pek çok iyileştirmeye gereksinim sürmektedir.

31 Aralık 2019'da Çin'in Hubei eyaletinin Wuhan şehrinde yeni tip koronavirüsün insanlarda hastalık yaptığı saptanmış ve hastalığın adı COVID-19 olarak kabul edilmiştir (Til, 2020). Hastalık, hakkında yeterince bilgi sahibi olunmaması nedeniyle iyice yayılmış ve Dünya Sağlık Örgütü tarafından 11 Mart 2020 tarihinde salgın olarak kabul edilmiştir (WHO, 2020). Eğitim, sağlık ve sosyoekonomik yaşamın her alanında olumsuz etkileri görülen bu virüs toplumu hazırlıksız yakaladığından dolayı ekonomide, sağlıkta, sosyal yaşamda krize neden olarak var olan düzeni yeniden şekillenmeye ve köklü değişimlere zorlamaktadır (Alpago ve Alpago-Oduncu, 2020). Dünya mevcut Koronavirus hastalığı ile başa çıkmaya çalışırken Covid krizinin ardından birçok ülke "evde kalmak" için tedbirler almıştır. Bu tedbirler uygulanmaya başlandığından beri kadına yönelik şiddet vakalarında da dünya genelinde artışlar görülmüştür. Gelir kaybı, işsizlik ve özellikle artan ekonomik güvencesizlik kaybı nedeniyle şiddete başvuran erkeklerin sayısında artışlar yaşanmıştır. Ekonomik istikrarsızlık alkol tüketiminde artışa, bu durum da ev içi şiddetin artmasina neden olmuştur (Vora, Malathesh, Das ve Chatterjee 2020). Birleşmiş Milletler Nüfus Fonu (UNFPA), COVID-19 salgınının 2030 
yılına kadar toplumsal cinsiyete dayalı şiddeti sonlandırmaya yönelik kaydedilen ilerlemede üçte bir oranında gerilemeye neden olacağını, sokağa çıkma yasağ 6 ay boyunca devam ederse toplumsal cinsiyete dayalı şiddet vakalarına 31 milyon yeni vakanın ekleneceğini, sokağa çıkma yasağının devam ettiği her 3 ay için, toplumsal cinsiyete dayalı şiddet vakalarına 15 milyon yeni vakanın ekleneceğini öngörmektedir (UNFPA, 2020). Türkiye Kadın Dernekleri Federasyonu, 2019 yılı Mart ayı ve 2020 yılı Mart ayında acil yardım hattına gelen ihbarlar karşılaştırıldığında fiziksel şiddetin \%81, psikolojik şiddetin ise \%93 oranında arttığını, hukuki desteğe ulaşamayan kadınların oranının \%96 olduğunu belirtmektedir (TKDF, 2020). Kadın Cinayetlerini Durduracağız Platformu ; 2021 yılı haziran ayına kadar 112 kadın cinayetinin, 79 şüpheli kadın ölümünün gerçekleştirildiğini bildirmiştir. 2020 yılında ise 300 kadın cinayeti, 171 şüpheli kadın ölümü gerçekleşmiştir (Kadın Cinayetlerini Durduracağız Platformu)

Tanrıverdi ve Şıpkın (2008) kadına yönelik şiddet ile ilgili yaptıkları çalışmada; katılımcı kadınların büyük bir çoğunluğunun evliliği boyunca en az bir kez eşi tarafından şiddet gördüğünü belirlemişlerdir. Özyurt ve Deveci (2010) kadınların \%57.8'ine eşi tarafından çoğunlukla fiziksel şiddet olmak üzere sözel ve cinsel şiddet uygulandığını, Tel, Kocataş, Güler, Tel Aydın ve Akgül Gündoğdu (2019) ise kadınların \%30.5' inin eşinden şiddet gördüğünü saptamışlardır.

Ceyhan (2014) yazılı medyada kadına yönelik şiddet haberlerini incelediği araştırmasında; kadına yönelik şiddeti uygulayanların yarısından çoğunun mağdurun kocası-eski kocasının $(\% 53,8)$ olduğunu belirlemiştir. Hacettepe Üniversitesi Nüfus Etütleri Enstitüsü tarafından gerçekleştirilen Türkiye'de Kadına Yönelik Aile İçi Şiddet Araştırması (2014) sonuçları kadınların \%36'sının yaşamının herhangi bir döneminde eşi veya birlikte olduğu erkeklerin fiziksel şiddetine, $\% 44$ 'ünün psikolojik şiddetine, $\% 12$ 'sinin cinsel şiddetine ve \%30'unun ise ekonomik şiddetine maruz kaldığını bildirmektedir.

Erden ve Akdur (2018) Türkiye'de kadına yönelik aile içi şiddet ve kadın cinayetlerini araştırdıkları çalışmalarında; kadınların \%65.1'inin partneri, \%41.6'sının resmi nikâhlı eşi, \%4.8'inin eski eşi, \%3'ünün dini nikâhlı eşi tarafından öldürüldügünü göstermişlerdir. Çalışmada ayrıca kadınların \%37.3'ü tartışma yüzünden, \%11.3'ü kıskançlık ve eşini aldattığı şüphesi, \%11'i boşanmayı ya da ayrılmayı talep etmesi nedeniyle, \%5.4'ü eski eşinin barışma talebini ya da kendisine gelen ilişki talebini reddettiği için öldürülmüştür. 
Ülkemizdeki şiddet haberleri bölgeler bazında bakıldığında; Bianet'in 2013-2015 yılları arasında basına yansıyan kadına yönelik şiddet haberlerinin incelendiği çalışmasında en çok şiddet haberinin Marmara bölgesinden geldiği belirtilmektedir (Teyitdosya, 2021). Türkiye'de Kadına Yönelik Aile İçi Şiddet Araştırması (2014) Türkiye'de fiziksel şiddetin yaşanması açısından, bölgeler arasında belirgin bir farklılaşma olduğunu, Doğu Karadeniz bölgesinde yaşayan kadınlar arasında fiziksel şiddete maruz kalma oranı \%26.8 iken Orta Anadolu bölgesindeki kadınlar arasında bu oran'ın \%42.8 olduğunu ve bunu \%42.2 ile Batı Anadolu Bölgesi'nin takip ettiğini göstermektedir.

Medyada şiddet haberleri genellikle hassas olan gruplar yani kadın ve çocuklar üzerinden işlenmektedir. Yaşanılan şiddetin döngüsü erkekten kadına - kadından çocuğa şeklindedir. Kadına yönelik şiddet toplumsal cinsiyet eşitsizliğinden doğmakta olup kadınlara uygulanan şiddet toplumda ikincil konuma itilmelerinden kaynaklanmaktadır (Yazıcı ve Şahbaz, 2020). Medyanın toplumu yönlendirici etkisinden dolayı kadına yönelik şiddet haberlerinin incelenmesi bu bakımdan önem taşımaktadır. Tüm bu bilgiler ışığında bu çalışma Koronavirüs salgınının kadına yönelik şiddet üzerine etkisinin yazılı basına yansıyan olgular üzerinden incelenmesi amaçlanmaktadır.

\section{Yöntem}

Pandeminin kadına yönelik şiddet üzerine etkisinin yazılı basına yansıyan olgular üzerinden incelenmesi amacıyla yürütülen bu çalışmada anaakım basinda tirajı en yüksek üç ulusal gazete (Hürriyet-195.774 Sabah-190.819 ve Sözcü-185.030) pandemi öncesi (10.03.2019-10.03.2020) ve pandemi dönemini (11.03.2020-10.03.2021) kapsayacak şekilde retrospektif olarak incelenmiştir. Ele alınan gazetelerin web sayfalarında "kadına yönelik şiddet," "kadın cinayeti," "öldürülen kadınlar," "namus ve töre cinayeti," "kadın kurban," "kadın istismarı" ve "darp edilen kadınlar" anahtar sözcükleri kullanılarak tarama yapılmıştır. Çalışmanın örneklemini bu gazetelerde belirtilen tarihlerde yer alan kadına yönelik şiddet haberleri oluşturmaktadır. Farklı gazetelerde yer alan aynı haber ya da haftanın farklı günlerinde tekrar yayımlanan aynı haber bir kez ele alınmıştır. İncelenen haberlerden 45 'inin aynı haber olması, 21'inin incelenen bilgilere yer vermemiş olması nedeni ile bu haberler örneklemden çıartılmıştır. Buna göre pandemi öncesi 98 ve pandemi döneminde 
138 olmak üzere toplam 236 habere ulaşılmış, haberler; kadının yaşı, medeni durumu, haberin geçtiği bölge, şiddetin türü, nedeni, uygulanma şekli, yeri, zamanı, kadının fail ile yakınlığı ve şiddet olayının sonucu ve şiddet sonrası failin durumu değişkenlerine göre gruplandırılmış ve sonuçlar yüzdelik olarak değerlendirilmiştir.

\section{Bulgular}

Yayımlanan şiddet haberlerinin 98 tanesi pandemi öncesini, 138 tanesi de pandemi dönemini kapsamaktadır. İncelenen şiddet haberlerinde yer alan

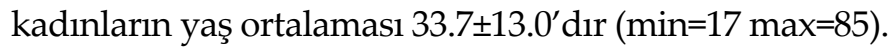

Tablo 1. Gazete haberlerinde şiddet gören kadınların medeni durumu

\begin{tabular}{lcccc}
\hline Medeni durum & \multicolumn{2}{c}{ Pandemi Öncesi } & \multicolumn{2}{c}{ Pandemi Dönemi } \\
\cline { 2 - 5 } & $\mathbf{n}$ & $\mathbf{\%}$ & $\mathbf{n}$ & $\mathbf{\%}$ \\
\hline Evli & 45 & 45.9 & 68 & 49.3 \\
Bekar & 36 & 36.7 & 42 & 30.4 \\
Dini nikahlı birliktelik & 17 & 17.4 & 28 & 20.3 \\
TOPLAM & 98 & 100.0 & 138 & 100.0 \\
\hline
\end{tabular}

Tablo 1'de gazete haberlerinde şiddete uğrayan kadınların medeni durumu incelendiğinde, yarıya yakınının evli (pandemi öncesi \%45.9, pandemi dönemi \%49.3) olduğu, bunu bekarlar (pandemi öncesi \%36.7, pandemi dönemi \%30.4) ve dini nikahlı birliktelik yaşayanların (pandemi öncesi \%17.4, pandemi dönemi \%20.3) izlediği saptanmıştır. Özellikle evli olan kadınların şiddete uğrama sıklığının pandemi döneminde pandemi öncesine göre arttığı yönünde gazete haberlerine rastlanmıştır.

Tablo 2. Gazete haberlerinde kadına yönelik şiddetin geçtiği bölge

\begin{tabular}{|c|c|c|c|c|}
\hline \multirow[t]{2}{*}{ Bölge } & \multicolumn{2}{|c|}{ Pandemi Öncesi } & \multicolumn{2}{|c|}{ Pandemi Dönemi } \\
\hline & $\mathrm{n}$ & $\%$ & $\mathrm{n}$ & $\%$ \\
\hline Marmara & 27 & 27.5 & 35 & 25.4 \\
\hline Akdeniz & 22 & 22.5 & 27 & 19.6 \\
\hline İç Anadolu & 17 & 17.4 & 23 & 16.7 \\
\hline Güneydoğu Anadolu & 14 & 14.3 & 18 & 13.0 \\
\hline Ege & 10 & 10.2 & 21 & 15.1 \\
\hline Doğu Anadolu & 6 & 6.1 & 7 & 5.1 \\
\hline Karadeniz & 2 & 2.0 & 7 & 5.1 \\
\hline
\end{tabular}

Tablo 2'de kadına yönelik şiddet haberlerinin en fazla geçtiği bölge Marmara Bölgesi'dir (pandemi öncesi \%27.5, pandemi dönemi \%25.4). Marmara 
Bölgesi'ni sırasıyla Akdeniz Bölgesi (pandemi öncesi \%22.5, pandemi dönemi \%19.6) ve İç Anadolu Bölgesi (pandemi öncesi \%17.4, pandemi dönemi \%16.7) izlemektedir. Özellikle pandemi döneminde Ege Bölgesi'nde (\%10.2'den \%15.1'e) ve Karadeniz Bölgesi'nde (\%2.0'dan \%5.1'e) kadına yönelik şiddete dair gazete haberlerinde belirgin bir artış olduğu belirlenmiştir.

Tablo 3. Gazete haberlerinde kadına yönelik şiddet faillerinin yakınlık durumu

\begin{tabular}{lllll}
\hline Fail ile yakınlığı & \multicolumn{2}{c}{ Pandemi Öncesi } & \multicolumn{2}{c}{ Pandemi Dönemi } \\
\cline { 2 - 5 } & $\mathbf{n}$ & $\mathbf{9}$ & $\mathbf{n}$ & $\mathbf{\%}$ \\
\hline Eşi & 38 & 38.8 & 52 & 37.7 \\
Eski eşi & 13 & 13.3 & 30 & 21.7 \\
Birlikte yaşadığı kişi & 8 & 8.1 & 6 & 4.4 \\
İmam nikahlı birlikte yaşadığı kişi & 14 & 14.3 & 26 & 18.8 \\
Erkek arkadaş & 12 & 12.3 & 12 & 8.8 \\
Eski erkek arkadaş & 4 & 4.1 & 5 & 3.6 \\
Babası & 2 & 2.0 & 2 & 1.4 \\
Bakıcı & - & - & 2 & 1.4 \\
Diğer & 7 & 7.1 & 3 & 2.2 \\
\hline
\end{tabular}

Tablo 3'te kadına yönelik şiddet haberlerinin incelendiğinde eşi tarafından şiddete maruz kalanlar (pandemi öncesi \%38.8, pandemi dönemi \%37.7) ilk sırada yer almaktadır. Bunu sırasıyla pandemi öncesi dönemde kadının imam nikahlı birlikte yaşadığı kişi (\%14.3), pandemi döneminde ise eski eşi (\%21.7) izlemektedir.

Tablo 4. Gazete haberlerinde kadına yönelik şiddetin nedenleri

\begin{tabular}{lllll}
\hline Şiddet nedeni & \multicolumn{2}{c}{ Pandemi Öncesi } & \multicolumn{2}{c}{ Pandemi Dönemi } \\
\cline { 2 - 5 } & $\mathbf{n}$ & $\mathbf{\%}$ & $\mathbf{n}$ & $\mathbf{\%}$ \\
\hline Kıskançlık & 48 & 49.0 & 58 & 42.0 \\
Kadının ayrılmak istemesi & 21 & 21.4 & 38 & 27.5 \\
Alkol & 8 & 8.2 & 10 & 7.3 \\
Madde bağımlılığı & 3 & 3.1 & 4 & 2.9 \\
Geçimsizlik & 12 & 12.2 & 20 & 14.5 \\
Töre & 2 & 2.0 & 3 & 2.2 \\
Diğer & 4 & 4.1 & 5 & 3.6 \\
\hline
\end{tabular}

Tablo 4'te görüldüğü gibi, şiddet haberlerinde kadınlar hem pandemi öncesinde (\%49.0) hem de pandemi döneminde (\%42.0) en çok "kıskançlık" nedeni ile şiddete maruz kalmışlardır. Ayrılmak istediği için şiddete maruz ka- 
lanlar (pandemi öncesi \%21.4, pandemi dönemi \%27.5) ile ailedeki geçimsizlik nedeniyle (pandemi öncesi \%12.2, pandemi dönemi \%14.5) şiddet gören kadınlar da azımsanmayacak bir orandadır.

Tablo 5. Gazete haberlerinde kadına yönelik şiddetin türü

\begin{tabular}{lllll}
\hline Şiddet türü & \multicolumn{2}{l}{ Pandemi Öncesi } & \multicolumn{2}{l}{ Pandemi Dönemi } \\
\cline { 2 - 5 } & $\mathbf{n}$ & $\mathbf{\%}$ & $\mathbf{n}$ & $\mathbf{\%}$ \\
\hline Fiziksel & 81 & 82.7 & 110 & 79.7 \\
Cinsel & 4 & 4.1 & 6 & 4.3 \\
Fiziksel ve cinsel & 6 & 6.1 & 7 & 5.1 \\
Fiziksel ve duygusal & 5 & 5.1 & 11 & 8.0 \\
Fiziksel ve ekonomik & 2 & 2.0 & 4 & 2.9 \\
\hline
\end{tabular}

Tablo 5 incelendiğinde kadınların maruz kaldıkları şiddet türleri arasında fiziksel şiddet (pandemi öncesi \%82.7, pandemi dönemi \%79.7) ilk sırada yer almaktadır. Bunu sırasıyla fiziksel ve cinsel (pandemi öncesi \%6.1, pandemi dönemi \%5.1), fiziksel ve duygusal şiddete uğrayan kadınlar (pandemi öncesi \%5.1, pandemi dönemi \%8.0) izlemektedir.

Tablo 6. Gazete haberlerinde kadına yönelik şiddet olayının gerçekleşme şekli

\begin{tabular}{lllll}
\hline Şiddetin gerçekleşme şekli & \multicolumn{2}{l}{ Pandemi Öncesi } & \multicolumn{2}{l}{ Pandemi Dönemi } \\
\cline { 2 - 5 } & $\mathbf{n}$ & $\mathbf{0}$ & $\mathbf{n}$ & $\mathbf{\%}$ \\
\hline Ateşli silah ile öldürme & 21 & 21.4 & 37 & 26.8 \\
Ateşli silah ile yaralama & 14 & 14.3 & 24 & 17.4 \\
Kesici alet ile öldürme & 18 & 18.4 & 22 & 15.9 \\
Kesici alet ile yaralama & 12 & 12.3 & 9 & 6.6 \\
Darp & 25 & 25.5 & 32 & 23.2 \\
Cinsel istismar & 4 & 4.1 & 6 & 4.3 \\
Yakma & 2 & 2.0 & 4 & 2.9 \\
Boğma & 2 & 2.0 & 4 & 2.9 \\
\hline
\end{tabular}

Tablo 6' da gazete haberlerine yansıyan kadına şiddet olaylarında şiddetin gerçekleşme şekline göre incelendiğinde pandemi öncesi dönemde darp edilen kadınların (\%25.5), pandemi döneminde ise ateşli silah ile öldüren kadınların (\%26.8) birinci sırayı görülmektedir. Darp edilen kadınları pandemi öncesinde sırasıyla ateşli silah ile öldüren kadınlar (\%21.4) ile kesici alet ile öldürülen kadınlar (\%18.4) izle, pandemi döneminde darp edilen kadınlar (\%23.2) ikinci sırada gelmekte, onu ile ateşli silah ile yaralanan kadınlar (\%17.4) izlemektedir. 
Tablo 7. Gazete haberlerinde kadına yönelik şiddet olayının yaşandığı zaman

\begin{tabular}{lllll}
\hline Olayın zamanı & \multicolumn{2}{l}{ Pandemi Öncesi } & \multicolumn{2}{l}{ Pandemi Dönemi } \\
\cline { 2 - 5 } & $\mathbf{n}$ & $\mathbf{\%}$ & $\mathbf{n}$ & $\mathbf{\%}$ \\
\hline Gündüz & 45 & 45.9 & 62 & 44.9 \\
Akşam & 32 & 32.7 & 47 & 34.1 \\
Gece & 21 & 21.4 & 29 & 21.0 \\
\hline
\end{tabular}

Tablo 7'de incelenen haberlerde gündüz şiddete uğrayan kadınların önde geldiği (pandemi öncesi \%45.9, pandemi dönemi \%44.9) belirlenmiştir. Ardından akşam (pandemi öncesi \%32.7, pandemi dönemi \%34.1) ve gece (pandemi öncesi \%21.4, pandemi dönemi \%21.0) şiddete maruz kalan kadınlar gelmektedir.

Tablo 8. Gazete haberlerinde kadına yönelik şiddet olayının yaşandığı yer

\begin{tabular}{lllll}
\hline Olayın yeri & Pandemi Öncesi & \multicolumn{3}{l}{ Pandemi Dönemi } \\
\cline { 2 - 5 } & $\mathbf{n}$ & $\mathbf{\%}$ & $\mathbf{n}$ & \% \\
\hline Kendi evi & 48 & 49.0 & 62 & 44.9 \\
Sokak & 24 & 24.5 & 31 & 22.5 \\
Ailesinin evi & 18 & 18.4 & 34 & 24.6 \\
İsyeri & 4 & 4.1 & 5 & 3.6 \\
Araba & 2 & 2.0 & 3 & 2.2 \\
Otel/misafirhane & 2 & 2.0 & 3 & 2.2 \\
\hline
\end{tabular}

Tablo 8'de görüldüğü gibi, incelenen haberlere göre pandemi öncesi dönemde (\%49.0) ve pandemi döneminde (\%44.9) kendi evinde şiddet gören kadınlar önde gelmektedir. Ardından pandemi öncesinde sırasıyla sokakta (\%24.5) ve ailesinin evinde (\%18.4) şiddet görenler gelirken, pandemi döneminde ailesinin evinde (\%24.6) ve sokakta (\%22.5) şiddet gören kadınlar gelmektedir.

Tablo 9. Gazete haberlerinde kadına yönelik şiddet olayının sonucu

\begin{tabular}{lllll}
\hline Olayın sonucu & \multicolumn{2}{l}{ Pandemi Öncesi } & Pandemi Dönemi & \\
\cline { 2 - 5 } & $\mathbf{n}$ & $\mathbf{\%}$ & $\mathbf{N}$ & $\mathbf{\%}$ \\
\hline Ölüm & 56 & 57.1 & 86 & 62.3 \\
Yaralanma & 42 & 42.9 & 52 & 37.7 \\
\hline
\end{tabular}

Tablo 9'da gazete haberlerine yansiyan şiddet olayının sonucu incelendiğinde pandemi öncesinde ve pandemi döneminde şiddet gören kadınların ne yazık ki yarısından fazlası (pandemi öncesi \%57.1, pandemi dönemi \%62.3) hayatını kaybetmiştir. Özellikle bu oranın pandemi döneminde arttı̆̆ı görülmektedir. 
Tablo 10. Gazete haberlerinde kadına yönelik şiddet olayı sonrası failin durumu

\begin{tabular}{lcccc}
\hline Olayın sonucu & \multicolumn{2}{l}{ Pandemi Öncesi } & \multicolumn{2}{c}{ Pandemi Dönemi } \\
\cline { 2 - 5 } & $\mathbf{N}$ & \% & $\mathbf{N}$ & \% \\
\hline Tutuklu & 53 & 54.1 & 81 & 58.7 \\
Serbest & 33 & 33.7 & 44 & 31.9 \\
Kaçak & 8 & 8.2 & 7 & 5.1 \\
Ölü & 4 & 4.0 & 6 & 4.3 \\
\hline
\end{tabular}

Tablo 10 incelendiğinde gazete haberlerine yansıyan şiddet olayı sonrası faillerinin yarıdan fazlasının tutuklu (pandemi öncesi \%54.1, pandemi dönemi \%58.7) olduğu, özellikle tutukluluk halinin pandemi döneminde arttı̆̆ görülmektedir.

\section{Tartışma ve Sonuç}

Bu araştırma pandeminin kadına yönelik şiddet üzerine etkisinin yazılı basina yansiyan olgular üzerinden incelenmesi amaciyla yürütülmüştür.

Araştırma sonucunda gazete haberlerine yansıdığı şekliyle şiddete uğrayan kadınların büyük oranının evli olduğu, özellikle pandemi döneminde evli veya dini nikahlı birliktelik yaşayan kadınların şiddeti pandemi öncesine göre daha yoğun yaşadıkları görülmektedir.

Gazete haberlerine yansıyan kadına yönelik şiddetin Marmara Bölgesi'nde yoğun olarak yaşandığı, pandemi dönemindeki Ege ve Karadeniz Bölgesi'nde kadına yönelik şiddete ait gazete haberlerinde artış olduğu belirlenmiştir. Bianet'in çalışmasında da benzer şekilde en çok şiddet haberinin Marmara bölgesinden geldiği belirtilmektedir (Teyitdosya, 2021). Umut Vakfı'nın (2020) durum analizinde kadın cinayetlerine bölgeler bazında bakıldığında 2020 yılında 150 olayla Marmara Bölgesi ilk sırada gelmektedir. Bu durum Marmara bölgesinin kozmopolit bir yapıda olmasından ve nüfus yoğunluğundan kaynaklanmış olabilir.

Kadına yönelik şiddet haberleri incelendiğinde kadınların şiddete genellikle eşleri tarafından maruz kaldıkları görülmüştür. Ayrıca pandemi döneminde eski eşi ve imam nikahlı birlikte yaşadığı kişi tarafından şiddet gören kadınların oranında artış dikkat çekicidir. Benzer şekilde Tanrıverdi ve Şıpkın (2008), Özyurt ve Deveci (2010), Tel, Kocataş, Güler, Tel Aydın ve Akgül Gündoğdu (2019) çalışmalarında kadınların çoğunlukla eşi tarafından şid- 
dete maruz kaldığı belirlenmiş̧tir. Pandemi döneminde evde izolasyon ile birlikte, ev işlerinin yerine getirilmesindeki cinsiyet eşitsizliği, ekonomik sıkıntıların yol açtı̆̆ 1 psikolojik sorunlar, alkol tüketiminde artış gibi bir çok faktör kadına yönelik şiddeti arttırabilmektedir (Ünal ve Gülseren, 2020).

Araştırma sonuçlarına göre şiddet haberlerindeki kadınlar hem pandemi öncesinde hem de pandemi döneminde "kıskançlık" nedeni ile şiddete maruz kalmışlardır. Bununla birlikte kadınlar pandemi döneminde boşanma ya da ayrılmayı talep etmeleri nedeniyle şiddet yaşamışlardır. Erden ve Akdur (2018)'un çalışmaları da bu çalışma ile paralellik göstermektedir. Çalışmalarda da görüldüğü üzere ne yazık ki ülkemizde kadınlar kıskançlık ve boşanmayı isteme gibi nedenlerle şiddete maruz kalmaktadır. Bu istenmeyen durum töre, gelenek ve görenek adı altına saklanmaktadır.

Gazete haberlerine yansıyan kadına yönelik şiddet türleri arasında fiziksel şiddet ilk sırada yer almaktadır. Ataerkil ve geleneksel değerler, kadınların ekonomik özerklikten yoksunluğu ve düşük sosyoekonomik durum, fiziksel aile içi şiddet için risk faktörleridir. Tokuç, Ekuklu ve Avcıoğlu (2009) çalışmalarında genç yaşta evli, eğitim düzeyi düşük, herhangi bir işte çalışmayan ve ailelerinin kararı ile evlenmiş olan kadınların daha yoğun fiziksel şiddete maruz kaldıklarını saptamışlardır.

Gazete haberlerine yansıyan kadına şiddet vakalarının gerçekleşme şeklinin pandemi öncesi dönemde daha çok darp, pandemi döneminde ise ateşli silah ile öldürülme olduğu görülmektedir. Özellikle evde silah bulundurmak kadın cinayetleri için büyük risk teşkil etmektedir. Bu durum ateşli silahlara ulaşmanın kolay olduğunu düşündürmektedir. Kadına yönelik şiddet sonucunda ateşli silah ile öldürülen kadınların fazla olması pandemi döneminde ateşli silahların satışının artışının (Güneş ve Yıldırım, 2019) bunda etkili olduğunu da akillara getirmektedir.

Gazete haberlerine yansıyan kadına yönelik şiddet çoğunlukla gündüz saatlerinde ve kadının kendi evinde gerçekleşmektedir. Kadınlar genellikle en güvende oldukları düşünülen yerde, yani evlerinde büyük tehlike altındadır. Özellikle pandemi döneminde bireylerin yasaklar nedeniyle evde bulunmaları bu sonuçları beraberinde getirmiş olabilir.

Araştırma sonucuna göre, pandemi öncesinde ve pandemi döneminde gazete haberlerinde şiddet gören kadınların ne yazık ki yarısından fazlası hayatını kaybetmiş ve özellikle pandemi döneminde şiddet faillerinin tutukluluk oranlarında artış dikkat çekicidir. 
Bu çalışma çeşitli sınırlılıkları beraberinde getirmektedir. Çalışmanın verileri sadece üç ana akım gazetenin çevrimiçi haberleri ve 10.03.201910.03.2021 tarihleri ile sınırlıdır. Bu yöntemde, kadına yönelik şiddet içeren tüm haberlerin çevrimiçi basına yansımamış olma ihtimali bulunmaktadır. Pandemi döneminde dünya genelinde uygulanan kısitlamaların bir sonucu olarak kadına yönelik şiddetin artmış olduğu bir gerçektir. Evlerde şiddet uygulayan partner ile kalmanın yanında, salgın hastalık ile ilgili korku ve belirsizlik, artan işsizlik ve ekonomik sıkıntıların yol açtı̆̆ psikolojik sorunlar, sağlık sistemine erişim zorlukları gibi bir çok faktörün kadına yönelik şiddeti arttırdığı görülmektedir; bu etkenlerin yanında en önemli sorun koruyucu ve önleyici destek mekanizmalarının salgın nedeniyle olumsuz etkilenmesidir. Bu konuda kadınların ekonomik anlamda özerk hale gelecek şekilde güçlendirilmesi, kadınlara yönelik iş imkanlarının geliştirilmesi, özellikle şiddetin yoğun yaşandığı bölgelerde bu duruma yerel yönetimler bazında hassasiyetle yaklaşılması ve risk haritalarının oluşturulmasının önemli olacağı düşünülmektedir. Cinsiyet eşitsizliğini savunan ve şiddeti meşrulaştıran sosyal normları ele alarak özellikle sivil toplum kuruluşlarının da kadının haklarını tanımaları, bağımsızlıkları konusunda bilgilendirilmeleri gerekmektedir. Aynı zamanda erkeklerin de kadının toplumdaki yeri ve hakları konusunda yapılacak olan eğitimlerde yer almalarının önemli olduğu görülmektedir. Özellikle kadın cinayetlerinde rol oynayan ateşli silahların satışının kısıtlanması konusunda gerekli yasal düzenlemelerin yapılması, şiddete maruz kalan kadının hukuki anlamda neler yapması gerektiği konusunda bilinçlendirilmesi, ayrıca bu süreçte psikolojik destek mekanizmalarının da artırılması önemli bir husustur. 


\title{
EXTENDED ABSTRACT
}

\section{Examination of the Impact of the Pandemic on Violence against Women on Written Press}

\author{
Hande Şahin- Aygen Çakmak- Yurdagül Erdem \\ Kırıkkale University
}

Domestic violence is a worldwide public health priority due to both the prevalence of violence and the violence-related morbidity and mortality rate. Violence against women and children is the most common form of domestic violence. There are different forms of violence against women, which are physical, psychological, sexual, and economic violence. Of women in Europe, $12 \%$ to $15 \%$ face domestic violence on a daily basis. The Federation of Women's Associations of Turkey (TKDF) determined that physical violence increased by $80 \%$, psychological violence increased by $93 \%$, and the demand for shelter increased by $78 \%$ during the pandemic.

On December 31, 2019, a new type of coronavirus was found to cause disease in humans in Wuhan city of Hubei province of China, and the name of the disease was accepted as COVID-19. While the world was trying to cope with the current Coronavirus disease, many countries took measures to "stay at home" after the COVID crisis. Since these measures have been implemented, there has also been an increase in cases of violence against women around the world. Economic instability has led to an increase in alcohol consumption, which has also led to an increase in domestic violence. When the notifications reported to the emergency helpline in March 2019 and March 2020 were compared, the Federation of Women's Associations of Turkey stated that physical violence increased by $81 \%$ and psychological violence increased by $93 \%$ and that the rate of women who could not reach legal support was $96 \%$.

In this study conducted to examine the effect of the pandemic on violence against women through the cases reflected in the print media, three national newspapers with the highest circulation in the mainstream media (Hürriyet-195,774 Sabah-190,819 and Sözcü-185,030) were retrospectively analyzed to cover the pre-pandemic (10.03.2019-10.03.2020) and the pandemic periods (11.03.2020-10.03.2021). The web pages of the newspapers 
addressed were reviewed by using the keywords "violence against women," "femicide," "murdered women," "honor killings," "female victim," "woman abuse," and "battered women." The news of violence against women in these newspapers on the specified dates constituted the study sample. The same news in different newspapers or the same news republished on different days of the week was discussed once. Accordingly, a total of 236 pieces of news were reached, including 98 pieces of news before the pandemic and 138 pieces of news during the pandemic. The news was grouped according to the variables of woman's age, marital status, region of the news, the type of violence, the reason for it, the way violence was used, the place and time of it, woman's relationship with the perpetrator, the result of the act of violence, and the status of the perpetrator after the violence, and the results were evaluated as percentages.

According to the study results, 98 and 138 of the violence news published covered the pre-pandemic period and the pandemic period, respectively. The mean age of the women included in the violence news analyzed was $33.7 \pm 13.0$. As they were reflected in the newspaper reports, it was observed that the majority of women who were subjected to violence were married and that the women who were married or had a relationship with religious marriage experienced violence more intensely, especially during the pandemic compared to the period before the pandemic. It was determined that violence against women reflected in newspaper reports was experienced intensely in the Marmara Region and that there was an increase in newspaper reports about violence against women in the Aegean and Black Sea Regions during the pandemic period. Likewise, it was indicated in the study of Bianet that most violent news came from the Marmara region. In the situation analysis of the Umut Foundation (2020), when femicides were examined on a regional basis, the Marmara Region ranked first with 150 incidents in 2020, which may be due to the cosmopolitan nature of the Marmara Region and its population density.

In the review, it was observed that women were generally subjected to violence by their husbands. Furthermore, the increase in the rate of women subjected to violence by their ex-husbands and the person with whom they lived with religious marriage during the pandemic was also remarkable. Likewise, in the studies conducted by Tanrıverdi and Şıpkın (2008), Özyurt and Deveci (2010), Tel, Kocataş, Güler, Tel Aydın and 
Akgül Gündoğdu (2019), it was determined that women were mostly subjected to violence by their husbands. During the pandemic period, many factors such as isolation at home, gender inequality in doing the housework, psychological problems caused by financial difficulties, and an increase in alcohol consumption may increase violence against women. According to the study results, women in the violence news were subjected to violence due to "jealousy" both before and during the pandemic. The studies carried out by Erden and Akdur (2018) are also parallel to this study. As seen in the studies, unfortunately, women in our country are subjected to violence for reasons such as jealousy and asking for a divorce. This undesirable situation is hidden under the name of moral laws, traditions, and customs.

Physical violence ranked first among the types of violence against women reflected in newspaper reports. Patriarchal and traditional values, women's lack of economic autonomy and low socioeconomic status are the risk factors for physical domestic violence. It was observed that the cases of violence against women reflected in newspaper reports were mostly in the form of battery during the pre-pandemic period and killing with a gun during the pandemic period. In particular, having a gun at home poses a great risk for femicides. Violence against women mostly occurs during daylight hours and in the woman's own home. Women are usually in great danger in the place considered to be the safest for them, namely in their home. Especially during the pandemic period, individuals' stay at home due to prohibitions may have brought along these results. According to the study results, it was remarkable that more than half of the women who were subjected to violence in the newspaper news before and during the pandemic, unfortunately, passed away, and that there was an increase in the detention rates of perpetrators of violence, especially during the pandemic.

It is a fact that violence against women has increased as a result of the restrictions implemented around the world during the pandemic period. In addition to staying with a violent partner at home, it is observed that many factors such as fear and uncertainty about the pandemic, psychological problems caused by increasing unemployment and financial difficulties, and difficulties in accessing the health system increase violence against women. In addition to these factors, the most important problem 
is that the protective and preventive support mechanisms have been adversely affected by the pandemic. Especially non-governmental organizations should also recognize women's rights and be informed about their independence by addressing the social norms that advocate gender inequality and justify violence. It is also observed that it is important for men to participate in training on the place and rights of women in society.

\section{Kaynakça/References}

Aile, Çalışma ve Sosyal Hizmetler Bakanlığı (2009). Türkiye'de kadına yönelik aile içi şiddet araştırması. Ankara: TC Başbakanlık Kadının Statüsü Genel Müdürlüğü. 12 Şubat 2021 tarihinde https://ailevecalisma.gov.tr/ uploads/ksgm/ uploads/pages/dagitimda-olan-yayinlar/turkiye-de-kadina-yonelikaile-ici-siddet-arastirmasi-ana-rapor.pdf adresinden erişildi.

Akhmedshina, F. (2020). Violence against women: A form of discrimination and human rights violations. Mental Enlightenment Scientific; Methodological Journal, 1(34),13-23.

Alpago, H. ve Alpago Oduncu, D. (2020). Koronavirüs salgınının sosyoekonomik sonuçları. IBAD Sosyal Bilimler Dergisi, 8, 99-114.

Ceyhan, S. (2014). Yazıl medyada kadına yönelik şiddet haberlerinde kullamlan dilin ve görsellerin incelenmesi. (Yayımlanmamış Uzmanlık Tezi). T.C. Aile ve Sosyal Politikalar Bakanlığı Kadının Statüsü Genel Müdürlüğü, Ankara.

Erden, G. ve Akdur, S. (2018). Türkiye'de kadına yönelik aile içi şiddet ve kadın cinayetleri. Klinik Psikoloji Dergisi, 2(3), 128-139.

Garcia-Moreno, C., Jansen HAFM, Ellsberg M., Heise, L. ve Watts C.H. (2006). WHO Multi-country study on women's health and domestic violence against women study team. Prevalence of intimate partner violence: findings from the WHO multi-country study on women's health and domestic violence. Lancet Lond Engl, 368, 1260-1269.

Gül-Sallan, S. ve Altındal, Y. (2015). Medyada kadın cinayeti haberlerindeki cinsiyetçi izler: Radikal gazetesi. Akdeniz Illetişim Dergisi, 24, 168-188.

Güneş, G. ve Yıldırım, B. (2019). Cinsiyet temelli bir savaş: Kadın cinayetlerinin medyada temsili üzerine bir değerlendirme. Toplum ve Sosyal Hizmet, 30(3), 936-964. 
Hacettepe Üniversitesi Nüfus Enstitüleri (2014). Türkiye'de kadına yönelik aile içi şiddet araştırması. 05 Şubat 2021 tarihinde http://wwww.hips.hacettepe.edu.tr/siddet2014/rapor/KKSATRAnaRaporKitap26 Mart.pdf adresinden erişildi.

Kadın Cinayetlerini Durduracağız Platform (2021). Veriler. 29 Haziran 2021 tarihinde http://kadincinayetlerinidurduracagiz . net /kategori / veriler?sayfa=2 adresinden erişildi.

Özyurt, S. C. ve Deveci, A. (2010). Manisa'da kırsal bir bölgedeki 15-49 yaş evli kadınlarda depresif belirti yaygınlığı ve aile içi şiddetle ilişkisi. Türk Psikiyatri Dergisi, 21(1), 1-7.

Resmi Gazete (2012). Ailenin korunması ve kadına karşı şiddetin önlenmesine dair kanun. 03 Mart 2021 tarihinde https://www.ailevecalisma.gov. tr/uploads / chgm/uploads/ pages/ kanunlar/6284-sayili-ailenin-korunmasi-vekadina-karsi-siddetin-onlenmesine-dair-kanun.pdf. adresinden erişildi.

Stöckl, H., Devries, K., Rotstein, A., Abrahams, N., Campbell, J., Watts, C. ve Moreno, C. G. (2013). The global prevalence of intimate partner homicide: A systematic review. The Lancet, 382(9895), 859-865.

Tanrıverdi, G. ve Şıpkın, S. (2008). Çanakkale'de sağlık ocaklarına başvuran kadınların eğitim durumunun şiddet görme düzeyine etkisi. Firat Tip Dergisi, 13(3), 183-187.

Tel,H., Kocataş, S., Güler, N., Tel Aydın, H. ve Akgül Gündoğdu,N. (2019). Evli kadınların aile içi şiddete maruz kalma durumu ve etkileyen faktörler. IBAD Sosyal Bilimler Dergisi, Özel Sayı, 256-264.

Teyitdosya (2021). Veriler Türkiye'de kadına yönelik şiddetin en az ve en çok olduğu kentler hakkında ne söylüyor? 02 Ocak 2021 tarihinde https://teyit.org/veriler-turkiyede-kadina-yonelik-siddetin-en-az-ve-en-cok-oldugu-kentler-hakkinda-ne-soyluyor adresinden erişildi.

Til, A. (2020). Yeni koronavirus hastalığı (Covid-19) hakkında bilinmesi gerekenler. Ayrmtı Göller Bölgesi Aylık Ekonomi ve Kültür Dergisi, 8(85), 54-57.

TKDF (2020). Türkiye Kadın Dernekleri Federasyonu. TKDF'den vahim tablo: Koronavirüs günlerinde kadına yönelik şiddet yüzde 80 arttı. 12 Şubat 2021 tarihinde $h$ ttps://www.evrensel.net/haber/ 401726 / tkdfdenvahim-tablokoronaviru s-gunlerinde-kadina-yonelik-siddet-yuzde-80-artti adresinden erişildi.

Tokuç, B., Ekuklu,G. ve Avcioğlu, S. (2010). Domestic violence against married women in Edirne. J Interpers Violence, 25(5), 832-847. 
TUIK (2014). Türkiye'de kadına yönelik aile içi şiddet araştırması, 2014 Mikro Veri Seti. 05 Mart 2021 tarihinde https://tuikweb.tuik. gov.tr /MicroVeri/KYAS 2014/ozet-tablolar/index.html adresinden erişildi.

Umut Vakfı (2020). 2020 Ylı kadın cinayetleri haritası. 23 Mart 2021 tarihinde http://umut.org.tr/umut-vakfi-2020-yili-kadin-cinayetleri-haritasil adresinden erişildi.

UNESCAP (2021). The Covid-19 pandemic and violence against women in Asia and the Pacific. the social development division of the United Nations Economic and Social Commission for Asia and the Pacific. 22 Mart 2021 tarihinde https://www.unescap.org/sites/default/ files/ 20201123_SDD_Policy_Paper\%20Covid-19-VAW.pdf. adresinden erişildi.

UNFPA (2020). COVID-19 Salgınının toplumsal cinsiyete dayalı şiddeti, kadın sünnetini ve çocuk yaşta evliliği sona erdirme çabaları ile aile planlaması üzerindeki etkisi. 11 Şubat 2021 tarihinde https://turkey.unfpa.org/sites/default/files/pub-pdflCOVID 19un DunyayaEtkileri Arastirma Raporu.pdf adresinden erişildi.

Ünal,B. ve Gülseren, L. (2020). COVID-19 pandemisinin görünmeyen yüzü: Aile içi kadına yönelik şiddet. Klinik Psikiyatri Dergisi, 23(Ek 1), 89-94.

Vora, M., Malathesh, B.C., Das, S. ve Chatterjee, S.S. (2020). COVID-19 and domestic violence against women. Asian Journal of Psychiatry, 53,1-12.

Yazıcı, F. ve Şahbaz Değer, Y. (2020). Toplumsal cinsiyet bağlamında kadına yönelik şiddet ve Türkiye'de yazılı basına yansıması. Intermedia International e-Journal, 2(12), 129-149.

Yüksel-Kaptanoğlu, İ. (2018). Kadınlara yönelik şiddet ve toplumsal cinsiyet eşitliği haritalama ve izleme çalışması, Ceid Yayınları: 6 (1. Baskı). Ankara: Nika Yayınevi. 1. Baskı. 04 Nisan 2021 tarihinde http://www. ceidizleme .org / medyaldosya/105.pdf. adresinden erişildi.

World Health Organization (2013). Global and regional estimates of violence against women: Prevalence and health effects of intimate partner violence and non-partner sexual violence. Geneva: World Health Organization. 02 Nisan 2021 tarihinde https://apps.who.int/iris /bitstream/handle /10665/85239/9789241564625 eng.pdf;jsessionid= adresinden erişildi.

World Health Organization [WHO]. (2020). Q\&A on coronaviruses (COVID-19). 11 Mart 2021 tarihinde https://www.who.int /emergencies / diseases/novelcoronavirus-2019 adresinden erişildi. 


\section{Kaynakça Bilgisi / Citation Information}

Şahin, H., Çakmak, A. ve Çakmak, Y. (2021). Pandeminin kadına yönelik şiddet üzerine etkisinin yazılı basına yansıyan olgular üzerinden incelenmesi. OPUS-Uluslararası Toplum Araştırmaları Dergisi, 18(43), 7348-7367. DOI:10.26466//opus.947704. 